\section{Manual of Practical Dermatology}

By J. H. S. Petrit. Medicine in the Tropics Series. Pp. 219, illustrated. Churchill Livingstone, Edinburgh, London, 1983. £7.95.

This short dermatological paperback is one in the Churchill Livingstone series 'Medicine in the Tropics'. The author Dr John Pettit, Consultant Dermatologist, Kuala Lumpur, Malaysia, clearly states in the preface that the book is intended for doctors practising in outlying areas who have had little dermatological training; it is not intended for practising dermatologists or dermatologists in training.

There are four sections, the first is a short 10-page introduction dealing with the anatomy of the skin and the principles of therapy. There then follows a section on the more common skin diseases such as acne, eczema, psoriasis as well as the parasitic infections which include onchocerciasis, dracunculiasis, filiariasis and leishmaniasis conditions not commonly seen in this country. The third section contains the rarer skin diseases such as the bullous disorders, lupus erythematosus, lichen planus, hair loss and some deficiency disorders. Finally, there is a section on regional differential diagnosis for skin problems occurring at different sites on the body.

The book is a brave attempt to simplify dermatology for the nonspecialist, but I am uncertain as to how helpful it will be to them in arriving at the correct diagnosis, for without this treatment can be ineffectual or counter productive. There are over a hundred illustrations but the majority are in black and white, many of African and Asian skins, but it is often difficult to make a clinical diagnosis from a black and white photograph.

There are many useful paragraphs on therapy and the author has had wide experience of treating skin problems in the tropics and has many helpful suggestions especially when drugs and other resources are limited. I was, however, concerned that in a book of this kind the recommended starting dose of prednisolone in the management of pemphigus vulgaris was $500 \mathrm{mg}$ daily, when many specialists in this country would be unhappy about using over $200 \mathrm{mg}$ daily.

I am sure that there are many doctors who will enjoy reading this book and find parts of it helpful to them. I must admit that I found the over-simplification and layout of the book disjointed and irritating - but then it wasn't written with me in mind!

J. J. H. GILKES,

University College Hospital, London WCIE 6AJ.

Oral Rehydration Therapy: an Annotated Bibliography. A project of the WHO/PAHO Program for the Control of Diarrheal Diseases

Scientific Publication No. 445. 2nd edn. Pp. ix +172 , illustrated. Pan American Health Organization, Washington, 1983. \$6.00.

I was recently enquiring of a group of postgraduate medical students what had been, in their opinion, the most momentous advance in medicine in the past 30 years; many suggestions were offered but none included oral rehydration therapy (ORT)-mainly I think because the development of this therapy was so beautifully logical and so totally lacking in serendipity. The key finding was the demonstration that glucose enhances sodium absorption in the small bowel, that this was an active process, which also continued in spite of concurrent diarrhoea. After the demonstration that patients with cholera could be maintained in a positive metabolic state by ORT, the treatment was applied to other small bowel acute diarrhoeal states, to children (and eventually even to neonates) and last but not least, even to patients in Britain. The first edition of this annotated bibliography was published in 1980, and contained 133 abstracts; this second edition contained a further 144 abstracts mostly published between early 1980 and the end of 1982 . The bibliography is grouped into five chapters dealing with historical development of ORT, clinical trials, composition, impact and implementation. Papers which cover more than one section are referenced in each appropriate section, but are abstracted only once. The abstracts are clear, detailed, descriptive rather than critical and contain a minimum of numerical or statistical material-this may be a disadvantage.
Apart from this minor criticism, this is a book which is a must for anybody dealing with the management of diarrhoea-GPs, paediatricians, tropical medicine experts (since the bulk of diarrhoea is passed in the tropics), public health officials and many others. There cannot be many annotated bibliographies which are readable, but this one was. At only $\$ 6.00$ it is a marvellous bargain.

G. H. REE,

Hospital for Tropical Diseases, London NW1 OPE.

\section{Pearce's Medical and Nursing Dictionary and Encyclopaedia}

Fifteenth Edition. By Evelyn Pearce. 15th edn. Pp. 443. Faber, London, Boston, 1983. £6.95.

The new edition of Pearce's Medical and Nursing Dictionary and Encyclopaedia is a reasonably priced and portable book, more compact than its predecessor and, as a result of being almost completely rewritten, provides more entries in a quarter less space. But in its present form it is too much of a compromise. As a dictionary it often fails to define its own terms, for example 'amniocentesis' under 'spina bifida' and 'central-line' under 'intravenous injections'. As an encyclopaedia, it is the poorer for not using illustrations in support of its text and for failing to comment on popular present-day concepts such as 'Community Care' and 'Handicap'. Indeed topicality is an inconsistent feature for whilst reference is made to the introduction, in 1983, of $\mathrm{U} 100$ insulin the reader is given the out-dated term 'subnormal' as a substitute for 'moron'.

Reference books should stimulate enquiry but this one contrives to talk down to its reader by too frequent repetition of introductions such as 'this is ...' and of key words: 'talipes'. Talipes comes from $\ldots$. The consequent waste of space is compounded by the inclusion of an 18-page section of doubtful value covering obsolete entries preserved from older editions.

On the other hand very few references to other sources of information are included apart from a brief bibliography which has ended up back-to-front on the wrong pages. This carelessness extends also to the select list of organizations, a useful feature but one which does not include any of the professional nursing organizations.

Nurses frequently use verbal shorthand in the form of abbreviations, many of which appear in the text. But they are found only by chance and the book's usefulness would have been enhanced by devoting some of its precious space to a list of abbreviations with appropriate cross references.

It is disappointing that this book in its 15 th edn. and 50th year appears in a unworkmanlike form that compares badly with other reference books to which nurses and students have ready access.

M. P. CofFEY,

Whittington Hospital London NI9 5NF.

\section{Primary Membership Video Series. A Course Designed to Help} Candidates Prepare for the MRCP (Part 1) Examination

By JoHN DAVIES. 22 Video Tape Lectures + M.C.Q. book. Dr John Davies, Postgraduate Medical Teaching Services, 34 Ivere Drive, Barnet, Herts, EN5 1AS. $£ 1,350$ (22 cassettes +10 M.C.Q. books), (exclusive of V.A.T., postage and packing).

The Course consists of 22 cassettes and 10 multiple choice question books. The cost is $£ 1,350$, exclusive of VAT.

This review is based on a 15 -min promotional VHS video cassette, obtainable from the Course Organizer at a price of $£ 10.00$, and a sample book of MCQs.

This is a novel but unsatisfactory way for a book or audio-visual series to be reviewed. The sample tape is compiled by the Course Organizer, and there is no guarantee that it is representative of the tapes as a whole. While appreciating that the whole series is expensive, trying to base a review of the series as a whole on a 